\title{
BMJ Global Health Eliminating malaria in conflict zones: public health strategies developed in the Sri Lanka Civil War
}

\author{
Abrar Ahmed (10 , 1,2 Kara Grace Hounsell, ${ }^{3}$ Talha Sadiq, ${ }^{4,5}$ Mariam Naguib, ${ }^{3}$ \\ Kirstyn Koswin, ${ }^{4,6}$ Chetha Dharmawansa, ${ }^{7}$ Thavachchelvi Rasan, ${ }^{8}$ \\ Anita M McGahan (1D) 4,9
}

\begin{abstract}
To cite: Ahmed A, Hounsell KG, Sadiq T, et al. Eliminating malaria in conflict zones: public health strategies developed in the Sri Lanka Civil War. BMJ Global Health 2021;6:e007453. doi:10.1136/ bmjgh-2021-007453
\end{abstract}

Handling editor Seye Abimbola

Received 20 September 2021 Accepted 29 November 2021

\section{Check for updates}

(c) Author(s) (or their employer(s)) 2021. Re-use permitted under CC BY-NC. No commercial re-use. See rights and permissions. Published by BMJ.

For numbered affiliations see end of article.

Correspondence to Dr Anita M McGahan; anita.mcgahan@rotman. utoronto.ca

\section{ABSTRACT}

Despite the 26-year long civil war, Sri Lanka was declared malaria-free by WHO in 2016. This achievement was the result of nearly 30 years of elimination efforts following the last significant resurgence of malaria cases in Sri Lanka. The resurgence occurred in 1986-1987, when about 600000 cases of malaria were detected. Obstacles to these efforts included a lack of healthcare workers in conflict zones, a disruption of vector control efforts, gaps in the medication supply chain, and rising malaria cases among the displaced population.

This article seeks to describe the four strategies deployed in Sri Lanka to mitigate the aforementioned obstacles to ultimately achieve malaria elimination. The first approach was the support for disease elimination by the government of Sri Lanka and the Liberation Tamil Tigers of Elam. The second strategy was the balance of centralised leadership of the federal government and the decentralised programme operation at the regional level. The third strategy was the engagement of nongovernmental stakeholders to fill in gaps left by the conflict to continue the elimination efforts. The last strategy is the ongoing efforts by the government, military and non-profit organisations to prevent the reintroduction of malaria. The lessons learnt from Sri Lanka have important implications for malaria-endemic nations that are in conflict such as Ethiopia, Afghanistan, Yemen and Somalia. To accomplish the World Health Assembly goal of reducing the global incidence and mortality of malaria by $90 \%$ by 2030 , significant efforts are required to lessen the disease burden in conflict zones. In addition to the direct impacts of conflict on population health, conflicts may lead to increased risk of spread of malaria, both within a country and consequently, abroad.

\section{INTRODUCTION}

In 2015, the World Health Assembly resolved to eliminate malaria in 35 nations, and to reduce its global incidence and mortality by at least $90 \%$ by $2030 .{ }^{1}$ Sri Lanka is a model nation as it received certification of malaria elimination in 2016 from WHO. This achievement came despite the country being in a civil war for much of the elimination campaign. ${ }^{2}$

\section{Summary box}

- Cooperation towards disease eradication despite opposing military or political interests is essential to keeping healthcare systems in conflict zones operational, thereby ensuring conflict-affected individuals can access care for malaria and benefit from preventative measures.

- Centralised leadership from the federal government ensures strong national malaria policy, and prevents redundancies in the work done by non-governmental stakeholders, while decentralised programme operations ensures national policy is adaptable to the different challenges faced by different regions in a country.

- Non-profit and/or private stakeholders can help to fill in the gaps in the healthcare system caused by conflict as they are often perceived as neutral parties and can therefore manoeuvre areas that may be otherwise restricted.

- After a nation eliminates malaria, vigilance is stil required to prevent the reintroduction of the disease.

The history of Sri Lanka is closely linked to malaria, as the country endured epidemics every 3-5years during the first half of the 20th century. The last malaria epidemic broke out in 1986 in the city of Polonnaruwa, North Central Province, the largest province in the country. ${ }^{3}$ This coincided with the civil war between the Sri Lankan government (GoSL) and the Liberation Tigers of Tamil Eelam (LTTE). The conflict, (1983-2009) was concentrated in the north-eastern regions of the country, coinciding with the epidemic that spread nationwide with roughly 600000 cases detected in 1986-1987 (figure 1). ${ }^{3-5}$

The north-eastern region is the dry zone, receiving the least amount of rainfall in the country. ${ }^{6}$ When it does rain, stagnant pools of water form, which serve as breeding grounds for the Anopheles mosquito, the vector for malaria. Consequently, the conflict zone had 


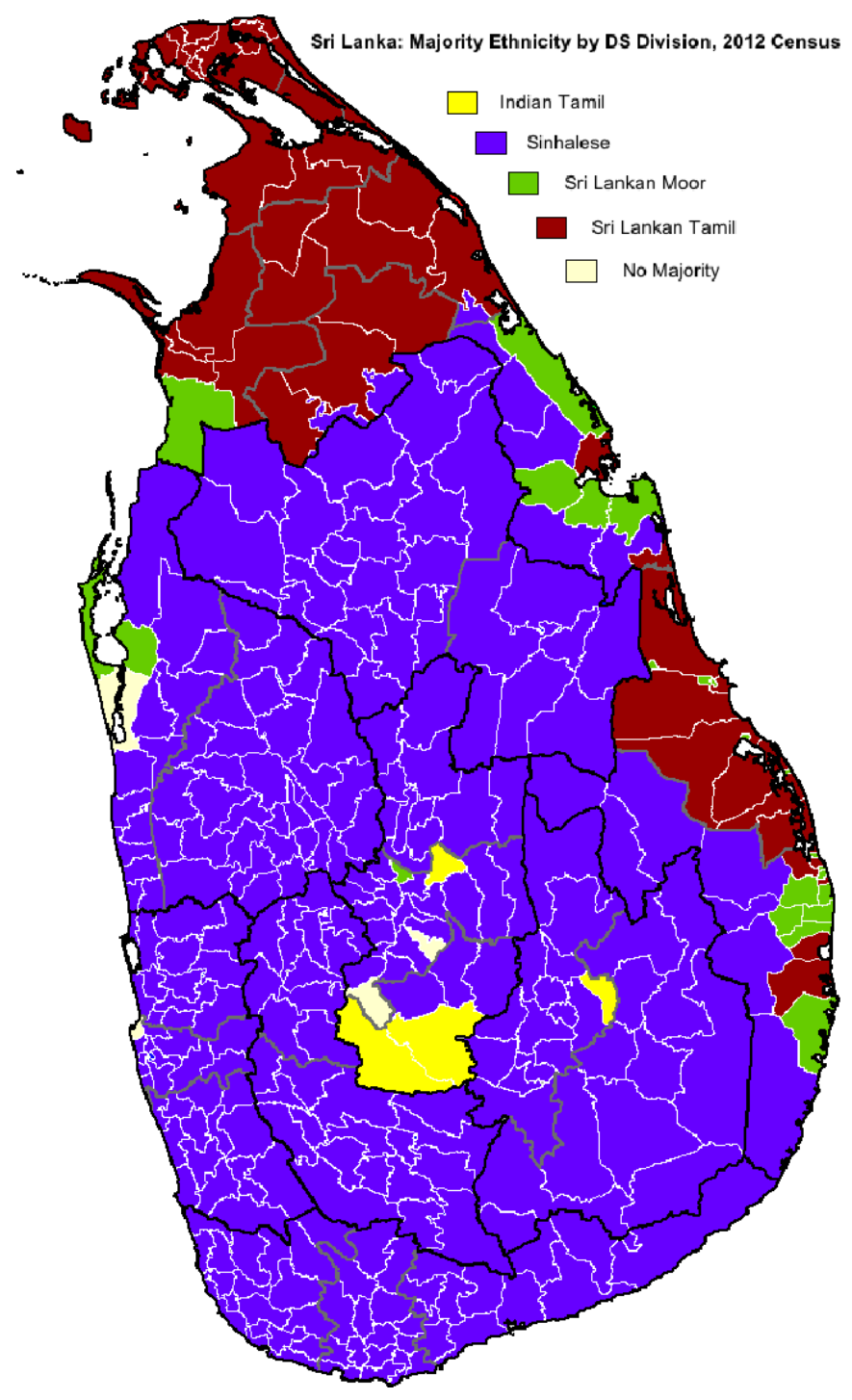

Figure 1 Eliminating Malaria in Conflict Zones: Public Health Strategies Developed in the Sri Lanka Civil War. Map of Sri Lanka showing majority ethnicity according to the 2012 census. Wikipedia. Demographics of Sri Lanka. Wikipedia. org 2013.The Northern regions of the country are dominated by the Tamil-speaking people of Sri Lanka. The rest of the nation is primarily dominated by the Sinhalese speaking people of Sri Lanka. Source: Wikipedia available under a Creative Commons license. https://documentcloud.adobe. com/link/review?uri=urn:aaid:scds:US:8f0ba4ce-5549-4242950d-476b331a4075\#pageNum=1.

the highest malaria incidence in the nation. By 1996, $41 \%$ of malaria cases were reported in the north-eastern provinces. ${ }^{7}$ However the number of cases in Sri Lanka fell throughout the conflict, with a near $70 \%$ reduction between 2000 and 2001.

This paper seeks to highlight strategies used in Sri Lanka to eliminate malaria in spite of the barriers posed by conflict. Sri Lanka's elimination campaign offers lessons for other malaria-endemic nations that are active conflict zones. Wars can cause increased malaria spread by stopping people from accessing preventative measures, ${ }^{8}$ health services and treatment, ${ }^{9}$ and forcing them into contact with anopheles mosquitoes while taking irregular travel methods. ${ }^{10}$

To learn how the nation managed to succeed we interviewed individuals in Sri Lanka that were involved in the elimination campaign in June 2018. The interviews were mainly conducted during our field work in Sri Lanka, while some were conducted in Toronto over platforms such as Skype and Zoom. These interviews were conducted in a semi structured manner, either over the phone or in person. The questions that were determined beforehand came as a result of identifying gaps in the existing literature.

Thirty-one professionals were interviewed. Interviewees included individuals from various ethnic backgrounds and living in the former active conflict zones. Eight interviewees were from international organisations (World Bank, UNHCR, WHO and the International Organisation for Migration (IOM)). Two interviewees were physicians from the academic sector. Two interviewees were from non-governmental organisations. One interviewee was a member of the military. Fifteen interviewees were from the government. Three interviewees were physicians. The interviews were conducted by a team consisted of members of the University of Toronto (Abrar Ahmed, Mariam Naguib, Talha Sadiq, Kara Hounsell, Kirstyn Koswin) and Research Assistants from Sri Lanka (Chetha Dharmawansa and Thavachchelvi Rasan).

After conducting the interviews, we analysed the data by identifying common themes across our investigations. These common themes informed the conceptual framework used to identify the translatable lessons from Sri Lanka's elimination campaign. We strove to add nuance to existing research on Sri Lanka's malaria elimination by employing qualitative research methods. Patients and the public were not involved in the analysis of this work.

\section{COLLABORATION BETWEEN GROUPS INVOLVED IN THE CONFLICT}

Despite the conflict between the GoSL and the LTTE, they each had their own motivations to support the malaria elimination campaign. Research suggests that the GoSL feared recurrent epidemics and the spread of the disease across the country. ${ }^{2}$ Prior research shows that malaria cases in LTTE controlled regions in the North of the country were significant versus cases in the rest of the nation in 1998. ${ }^{11}$ If the populations living in conflict zones were not targeted, malaria remained a risk for the entire nation. However, an alternate view suggests that the GoSL used malaria outbreaks in LTTE-held regions to justify its significant military presence. ${ }^{12}$

The LTTE army was exposed to the Anopheles vector while fighting in the jungles in the northeastern regions of the country and, therefore, were at higher risk of malaria. ${ }^{2}$ This suggests that the LTTE's motivation was strategic as sick people make poor fighters. Interviewees also suggested that the long history of malaria epidemics 
in Sri Lanka and significant public education efforts have contributed to the common goal of malaria elimination, regardless of political affiliation. Additionally, the LTTE's motivations were political as their ability to provide a public health service such as malaria control was indicative of their legitimacy as a potential government for the Tamil people. ${ }^{12}$

Previous literature highlighted an informal collaboration between the groups that may have enabled the administration of malaria treatment to the population residing in conflict zones. ${ }^{27}$ However, the intricacies of this cooperation has not been previously described in the literature. The collaboration stemmed from the first ceasefire, which enabled a National Immunisation Day managed by healthcare professionals in the North and by leaders of the LTTE. Subsequent ceasefires, called 'Days of Tranquillity,' led to immunisation interventions focused on polio. The LTTE agreed as polio threatened the lives of children in the north-eastern provinces. These 1-day ceasefires occurred between 1995 and $2001 .^{13} 14$ Interviewees stated that this initial coordination enabled the indirect communication between the groups for the purpose of malaria control efforts.

Government employees in the North continued to receive salaries during the war, including Tamil employees in LTTE-controlled territory. This aided in the maintenance of the healthcare system in the Northeast of the country. Informants stated that, although there was no official agreement between the groups, communication between the Antimalarial Campaign (AMC) - the centralised governmental agency for malaria elimination efforts-and the LTTE was facilitated by AMC regional malaria officers (RMOs) (table 1), who were primarily Tamil and also paid by the GoSL.

The coordination between the government and the LTTE was necessary for the activities of the AMC. RMOs in the North were permitted by the LTTE and the GoSL to travel to Colombo, when travel was restricted between the North and South, for monthly meetings during which they conveyed information about malaria incidence. Additionally, following the restoration of entomological surveillance later in the conflict, RMOs in the

Table 1 Summary of the different organisations involved in Sri Lanka's malaria elimination campaign

\begin{tabular}{|c|c|}
\hline Partner & Role \\
\hline $\begin{array}{l}\text { Tropical and Environmental } \\
\text { Disease and Health Associate }\end{array}$ & $\begin{array}{l}\text { Involved in entomological and parasitological surveillance activities in conflict regions } \\
\text { Built mobile malaria clinics to treat vulnerable populations } \\
\text { Took part in data collection and its incorporation into national malaria database }\end{array}$ \\
\hline $\begin{array}{l}\text { The International Organisation for } \\
\text { Migration }\end{array}$ & Informed the AMC whenever migrants were coming from nations that were malaria endemic \\
\hline The military & $\begin{array}{l}\text { Senior staff are first educated by the AMC on malaria, in turn senior staff educate other personnel } \\
\text { Meet with RMOs once a month } \\
\text { Indoor residual spray in army camps } \\
\text { Uses active case detection in army camps } \\
\text { Personnel take part in public health lectures } \\
\text { Personnel aid help to eliminate larvae breeding grounds for dengue and malaria }\end{array}$ \\
\hline
\end{tabular}

AMC, Anti Malarial Campaign; GoSL, Government of Sri Lanka; ICRC, International Committee of the Red Cross; IOM, International Organization for Migration; LTTE, Liberation Tigers of Tamil Eelam; PHI, Public Health Inspector; RMO, regional malaria officer; TEDHA, Tropical and Environmental Disease and Health Associate; TEHS, Tamil Eelam Health Services; WHO, World Health Organization. 
North were able to apply to the AMC for supplies such as medications.

Malaria-endemic nations that are conflict zones may benefit from collaboration between groups involved in military conflict to eliminate the disease. There is a collective benefit from eliminating malaria as the disease does not discriminate based on political or military alliances. It is necessary to ensure the entire population can access treatment and preventative measures as malaria can spread from person to person. Collaboration helps to ensure health systems remain operational in conflict zones. Consequently, those residing in conflict zones or those displaced by the conflict can attain treatment or benefit from preventative measures.

\section{CENTRALISED LEADERSHIP WITH DECENTRALISED PROGRAMME OPERATION}

Interviewees stated that Sri Lanka's elimination campaign involved centralised leadership from the federal government. This enabled the AMC to ensure that only they acquired, stored and distributed anti-malarial medications. Antimalarials were only distributed to public hospitals while private clinics were required to contact the AMC for the necessary medications. This strategy enabled the AMC to develop a centralised database of individuals diagnosed with malaria. Before providing medications, the AMC required a positive malaria diagnosis confirmed through microscopy, ${ }^{15}$ which helped to strengthen surveillance and reduce breeding resistance.

The nation's centralised approach allowed for a coordinated response to the obstacles faced by the elimination campaign. For example, the AMC partnered with stakeholders such as the International Committee of the Red Cross (ICRC), Sarvodaya and the Tropical and Environmental Disease and Health Associate (TEDHA), to provide malaria treatment, entomological and parasitological services throughout the conflict (table 1).

Strong central leadership from the federal government is required for a nation's malaria elimination efforts. Sri Lanka's national government drafted policies that ensure effective medication supply management. This prevented wasteful use of drugs and enabled strong surveillance of disease cases. Moreover, strong central leadership is crucial when working with non-government stakeholders. With several organisations involved, redundancies in their roles pose a significant obstacle for an effective malaria elimination campaign. Leadership overseeing the campaign prevents this, through coordination of the involved organisations.

Malaria control programmes such as surveillance, parasitological and entomological activities were operated through a decentralised method with RMOs. ${ }^{16}$ Each province was accountable for their own malaria control activities led by local RMOs. According to interviewees, these officials had monthly meetings, which enabled interprovincial collaboration throughout the conflict. This decentralised approach ensured that national policy was adopted for local contexts and that AMC leaders took local issues into context when developing policy. For example, RMOs were employed to represent the central government in LTTE controlled areas which was critical to malaria control and elimination.

This suggests that malaria-endemic nations can benefit from decentralised programme operations. Different regional areas may face different challenges when targeting malaria. Therefore, national policy needs to be adaptable to fit this diversity to ensure each region can successfully eliminate malaria. Regional officials understand the challenges present in the areas in which they live. Their input helps ensure that policy fits the local context.

\section{STAKEHOLDERS FILLED GAPS RESULTING FROM CONFLICT FOR CONTINUED MALARIA ELIMINATION EFFORTS}

Despite the indirect collaboration between the GoSL and the LTTE, gaps remained in the healthcare system that prevented vulnerable populations from accessing malaria care. Our research revealed that these gaps were mediated by the LTTE, local and international non-profit organisations and private organisations. These stakeholders coordinated their efforts with the AMC.

\section{LTTE health system}

Informants explained that the LTTE developed a parallel health service (table 1). This system, composed of the Tamil Eelam Health services (TEHS) and the Thileepan medical services, included a battleground division and a division to serve civilians living in the territory, respectively. The TEHS branch was engaged in insecticide spraying and malaria treatment, while the Thileepan branch was composed of mobile units that facilitated healthcare access in remote regions such as Batticaloa. The TEHS was in contact with the AMC indirectly through volunteers, midwives and other front-line workers who reported to both groups.

With the exodus of healthcare professionals from conflict regions, two approaches to malaria control emerged. First, the University of Jaffna provided accelerated microscopy and parasitology training to labourers with high school diplomas. These labourers worked in the rural North to identify malaria cases after professional microscopists and parasitologists had left due to the conflict. Second, LTTE health professionals developed an accelerated medical training programme. Consequently, three dozen individuals were trained as 'medics' to work with government physicians in the North to deliver community medicine. Following the war these graduates stopped practicing, as it was not a recognised formal certification by the GoSL Ministry of Health.

\section{Non-profit organisations}

International Committee for the Red Cross

According to interviewees, the A-9 highway was the only landbased connection between Colombo and the Jaffna peninsula. It was closed several times during the war, ${ }^{1718}$ resulting 
in the interruption of the supply chain of antimalarials and pesticides to the north of the country. When the road was open, both the government and LTTE required their own individual clearance processes. The clearance time of 1-2 weeks could be shortened and facilitated by networks of individuals who were connected and perceived as neutral.

The ICRC ensured that antimalarial supplies sent from the GoSL entered LTTE territory (table 1). Medications were requested through the RMOs and underwent reviews by the Ministry of Defence and Ministry of Health before journeying across the A9 blockade facilitated by the ICRC. This occurred between 2006 and 2009 at the Ommanthai crossing, where both parties inspected the supplies. After 2009 there was a period of time when the A9 was not a viable option. Consequently, the ICRC arranged transportation by ship through the Trincomalee port in the East.

\section{Sarvodaya}

Sarvodaya contributed to malaria control in the northeastern provinces during the war (table 1). This civil society organisation was essential in augmenting public education to support elimination. It supported education by organising an annual Malaria Day in schools in partnership with the AMC throughout the 2000s. The organisation ran awareness campaigns to encourage the general public to seek early treatment. Sarvodaya distributed leaflets, created billboards and radio messages to ensure that the message was accessible.

Sarvodaya negotiated with the LTTE to provide longlasting insecticidal nets, ${ }^{19}$ as well as modified nets designed for use by displaced persons in the North. The organisation was able to distribute about 500000 nets during ceasefires in the north. This was possible because Sarvodaya was perceived as a neutral party and could reach areas inaccessible to others by working with state and non-state actors. Additionally, Sarvodaya staff members identified abandoned pits that could become Anopheles breeding grounds, and filled them up to prevent breeding. Staff also introduced fish to eat larvae in open bodies of water. These actions allowed the organisation to help improve malaria vector control.

\section{Private organisations}

Tropical and Environmental Disease and Health Associate

TEDHA was a private stakeholder that operated between 2009 and 2014 (table 1). ${ }^{20}$ The organisation improved activities related to entomological and parasitological surveillance in conflict regions such as Trincomalee and Kilinochchi. For example, TEDHA screened 994448 individuals for malaria between 2009 and $2014 .{ }^{20}$ This is comparable to the AMC, which screened 1102054 people. ${ }^{20}$ Together with the AMC, TEDHA built mobile malaria clinics to treat vulnerable and high-risk populations such as pregnant women and gem miners.

Local stakeholders are key to a successful malaria elimination campaign in nations that are in the midst of conflict. Non-profit and private organisations may be perceived as neutral and consequently may be able to enter regions that a government cannot due to conflict related restrictions. Those displaced by war or those living in conflict affected areas can then receive medical treatment and benefit from preventative measures such as education, and entomological and parasitological surveillance.

\section{PREVENTING THE REINTRODUCTION OF MALARIA}

The last indigenous case of malaria in Sri Lanka was eliminated in $2012,{ }^{3821}$ and the nation was declared malaria free in 2016 by WHO. ${ }^{22}$ Despite this achievement, Sri Lanka is at risk of malaria reintroduction through complacency, migration and dengue elimination efforts.

\section{Complacency}

Sustainable elimination is threatened by the government and stakeholders' reluctance to commit the time and resources to prevent the reintroduction of malaria in Sri Lanka. Sri Lanka has experienced malaria epidemics due to complacency in the past. As the nation approached elimination in the 1960s, government complacency resulted in a reintroduction of malaria in the 1970s. ${ }^{2}$ Interviewees warned that the disease could become 'forgotten' and important skills such as microscopy may be lost. To combat this, the AMC hosts training programmes to ensure that physicians maintain their skills to diagnose and treat malaria.

\section{Migration}

According to interviewees, the risk of malaria reintroduction through migration was identified by the IOM (table 1). Migrants are vulnerable to malaria as they may use irregular modes of travel and may have reduced access to the healthcare system. The IOM regularly informed the AMC when visitors and citizens arrived in Sri Lanka from malaria-endemic nations. AMC staff screened migrants and visitors at the international airport through interviews and blood smears. Those coming from endemic nations were more likely to be exposed to malaria, and thus contribute to the spread of malaria in regions in Sri Lanka where the Anopheles mosquito lives. Since the conflict, the number of people travelling to malaria-endemic countries has increased with the majority (97\% of the 4500) leaving to West Africa making reintroduction of malaria a continued threat. ${ }^{10}$ This threat was illustrated in 2014, when 32 cases of Plasmodium falciparum were found in 534 irregular migrants who returned to Sri Lanka from West Africa. ${ }^{23}$

Sustainable elimination is threatened by military personnel returning from peacekeeping missions in malaria-endemic nations. To mitigate this threat, the military worked with the AMC, to improve malaria awareness among its members (table 1). Senior staff are educated in predeployment classes led by the AMC. Afterwards, these senior officials trained other personnel. Additionally, the military met with the RMOs once a month, and employed indoor residual spraying in their army camps. The military also used active case detection with blood smears in their camps. Lastly, personnel living in camps take part in public health lectures led by the region's PHI (public health inspector). The PHI visited a designated camp each month to observe compliance, provide training and conduct analysis work. 


\section{Dengue}

After malaria was eliminated, Sri Lanka faced a second mosquito-based epidemic, dengue. In 2017, the nation had 186101 suspected cases and 440 deaths related to dengue. ${ }^{24}$ Key stakeholders stated that efforts to control dengue may contribute to the reintroduction of malaria. The national government employs the fogging method to control dengue throughout critical places including residential areas with a high number of dengue cases and in public institutions such as schools in the middle of every monsoon season. The pesticides used to fog the habitat of the Aedes mosquitoes (the dengue vector) are not effective against the Anopheles mosquitoes. With a focus on eliminating the Aedes mosquitoes, Sri Lanka is at risk of ineffective vector control against Anopheles mosquitoes. Additionally, because the focus is on dengue, there may be delays in diagnosing malaria. With so few cases of malaria, physicians may instead incorrectly diagnose febrile patients with dengue.

However, the overlap between malaria and dengue have also contributed to reinforcement of malaria control. For example, an interviewee stated that PHIs work with local police to inspect houses and government buildings for mosquito breeding grounds. Households may be penalised with a fine between 1000 and 5000 Sri Lankan rupees if breeding grounds are found. Additionally, the military's health services are part of a presidential task force for dengue as they help to clean up public spaces to eliminate larvae breeding grounds (table 1). These efforts help to eliminate the Aedes and Anopheles mosquitoes.

It is essential for malaria-endemic nations to remain vigilant even after eliminating the disease. Vigilance begins with the national government as this institution needs to invest the necessary time and resources for sustained elimination. Nations must first identify their individual risk factors for reintroduction, as these may vary from nation to nation, before developing strategies to control these threats. Such strategies may require the help of non-governmental stakeholders.

\section{CONCLUSION}

While the medical capacity required to address malaria is available, it is not widely accessible to hard-to-reach populations. It is crucial to ensure that every person can access the medical care necessary to diagnose and treat malaria, as the disease can spread throughout a population if left unchecked. Although Sri Lanka had the medical capacity to address malaria, the civil war created numerous challenges that initially resulted in the nationwide spread of the disease. We describe several specific strategies that enabled Sri Lanka to reach populations affected by conflict. These strategies included collaboration between groups involved in the conflict, centralised leadership and decentralised programme operations, stakeholder engagement to fill in gaps left by conflict and continuous efforts to prevent reintroduction of malaria. These approaches may improve malaria elimination efforts in active conflict zones, thus bringing us closer to a malaria free world.

\section{Author affiliations}

${ }^{1}$ Medicine, Western University Schulich School of Medicine \& Dentistry, London, Ontario, Canada

${ }^{2}$ Department of Human Biology, University of Toronto Faculty of Arts and Science, Toronto, Ontario, Canada

${ }^{3}$ Temerty School of Medicine, University of Toronto, Toronto, Ontario, Canada ${ }^{4}$ Munk School of Global Affairs and Public Policy, University of Toronto, Toronto, Ontario, Canada

${ }^{5}$ Natural Resources Canada, Ottawa, Ontario, Canada

${ }^{6}$ Global Affairs Canada, Ottawa, Ontario, Canada

${ }^{7}$ Department of Energy, Environment and Climate Change, Asian Institute of Technology, Khlong Nueng, Thailand

${ }^{8}$ Department of Fine Arts, University of Jaffna, Jaffna, Sri Lanka

${ }^{9}$ Rotman School of Management, University of Toronto, Toronto, Ontario, Canada

Acknowledgements We want to thank the Reach Alliance and in particular Dr. Joseph Wong for his guidance and leadership throughout the project. We would also like to thank Reach Alliance members Dr. Peter Chengming Zhang and Azana Hyder for their help throughout the writing process. We want to sincerely thank the participants who gave us their time and honesty, especially to Dr Sivarajah who passed away about 1 year after we had the opportunity of meeting him in his home in Jaffna.

Contributors AA is the first author and submitting author. He contributed to the development of the data collection tools, study conduction and analysis and interpretation of study findings. He wrote the manuscript and submitted the study. KGH contributed to the development of the data collection tools, study conduction and analysis and interpretation of study findings. MN contributed to the development of the data collection tools, study conduction and analysis and interpretation of study findings. TS contributed to the development of the data collection tools, study conduction and analysis and interpretation of study findings. KK contributed to the conduction of the study. CD contributed to the conduction of the study. TR contributed to the conduction of the study. AMM is the corresponding author and guarantor. She supervised and planned the study by designing the data collection tools, and interpretation of the study findings. AMM accepted full responsibility for the finished work and the conduct of the study. She had access to the data, and controlled the decision to publish.

Funding The study was funded by Mastercard Centre for Inclusive Growth.

Map disclaimer The inclusion of any map (including the depiction of any boundaries therein), or of any geographic or locational reference, does not imply the expression of any opinion whatsoever on the part of BMJ concerning the legal status of any country, territory, jurisdiction or area or of its authorities. Any such expression remains solely that of the relevant source and is not endorsed by BMJ. Maps are provided without any warranty of any kind, either express or implied.

Competing interests None declared.

Patient consent for publication Not applicable.

Ethics approval The research was approved by the Research Ethics Board in the Social Sciences and Humanities at the University of Toronto. The research was conducted through interviews of professionals during June of 2018. All interviews were conducted with professionals rather than patients or other vulnerable persons, and the interview protocol was approved by the University of Toronto Research Ethics Board.

Provenance and peer review Not commissioned; externally peer reviewed.

Data availability statement The supporting data is unavailable to be shared. Study participants did not agree for their data to be shared due to the nature of this research.

Open access This is an open access article distributed in accordance with the Creative Commons Attribution Non Commercial (CC BY-NC 4.0) license, which permits others to distribute, remix, adapt, build upon this work non-commercially, and license their derivative works on different terms, provided the original work is properly cited, appropriate credit is given, any changes made indicated, and the use is non-commercial. See: http://creativecommons.org/licenses/by-nc/4.0/.

\section{ORCID iDs}

Abrar Ahmed http://orcid.org/0000-0003-2202-9341

Anita M McGahan http://orcid.org/0000-0002-5584-8207

\section{REFERENCES}

1 World Health Organization. Global technical strategy for malaria 2016-2030. World Health Organization, 2015. 
2 Abeyasinghe RR, Galappaththy GNL, Smith Gueye C, et al. Malaria control and elimination in Sri Lanka: documenting progress and success factors in a conflict setting. PLoS One 2012;7:e43162.

3 Simac J, Badar S, Farber J, et al. Malaria elimination in Sri Lanka. J Health Spec 2017;5:60-5.

4 Fernando P. Past malaria epidemics in Sri Lanka - an analysis. Journal of the College of Community Physicians of Sri Lanka 2014;19:27-15.

5 Wijesundere DA, Ramasamy R. Analysis of historical trends and recent elimination of malaria from Sri Lanka and its applicability for malaria control in other countries. Front Public Health 2017;5:212.

6 van der Hoek W, Konradsen F, Perera D, et al. Correlation between rainfall and malaria in the dry zone of Sri Lanka. Ann Trop Med Parasitol 1997;91:945-9.

7 Sivarajah N. Health in wartime North of Sri Lanka: a Felicitation volume in honour of Dr. N. Sivarajah. Colombo,SL: Kumaran Book House, 2013

8 Spencer S, Grant AD, Piola P, et al. Malaria in camps for internallydisplaced persons in Uganda: evaluation of an insecticide-treated bednet distribution programme. Trans $R$ Soc Trop Med Hyg 2004;98:719-27.

9 Siriwardhana C, Wickramage K. Conflict, forced displacement and health in Sri Lanka: a review of the research landscape. Confl Health 2014;8:1-9.

10 Wickramage K, Premaratne RG, Peiris SL, et al. High attack rate for malaria through irregular migration routes to a country on verge of elimination. Malar J 2013:12:1-5.

11 Briët OJT, Gunawardena DM, van der Hoek W, et al. Sri Lanka malaria maps. Malar J 2003;2:22-10.

12 Decolonisation SKT. Development and disease: a social history of malaria in Sri Lanka. New Delhi, IN: Orient Blackswan, 2014.
13 Kleinfeld M. The Political Utility of the Nonpolitical Child in Sri Lanka's Armed Conflict. Ann Assoc Am Geogr 2009;99:874-83.

14 Reilley B, Simpson I, Ford N. Conflict in Sri Lanka: Sri Lanka's health service is a casualty of 20 years of war. Br Med $J$ 2002;324:1-6. 361

15 Dewanee Ranaweera A, Danansuriya MN, Pahalagedera K, et al. Diagnostic challenges and case management of the first imported case of Plasmodium knowlesi in Sri Lanka. Malar J 2017;16:126.

16 Premaratne R, Wickremasinghe R, Ranaweera D, et al. Technical and operational underpinnings of malaria elimination from Sri Lanka. Malar J 2019;18:256

17 Bouffard S, Carment D. The Sri Lanka peace process: a critical review. Journal of South Asian Development 2006;1:151-77.

18 Gunasekera K, Anderson W, Lakshmanan TR. Highway-induced development: evidence from Sri Lanka. World Dev 2008;36:2371-89.

19 Tudor Silva K, Navaratna H, Wanninayaka P. Malaria control through community action at the grass-roots: experience of the Sarvodaya malaria control research project in Sri Lanka from 1980 to 1986. World Health Organization, 1988: 1-75.

20 Fernando D, Wijeyaratne P, Wickremasinghe R, et al. Use of a public-private partnership in malaria elimination efforts in Sri Lanka; a case study. BMC Health Serv Res 2018;18:1.

21 World Health Organization. Eliminating malaria. World Health Organization, 2016: 1-28.

22 Bagcchi S. Sri Lanka declared malaria free. BMJ 2016;354:i5000.

23 Cousins S. Sri Lankans vigilant after Bidding farewell to malaria. Bull World Health Organ 2017;95:170-1.

24 Tissera HA, Jayamanne BDW, Raut R, et al. Severe dengue epidemic, Sri Lanka, 2017. Emerg Infect Dis 2020;26:682-91. 